\title{
Effect of processing options on ultra-low-loss lead-magnesium-niobium titanate thin films for high density capacitors
}

\author{
Wenbin Chen ${ }^{\text {a,* }}$, Kevin G. McCarthy ${ }^{\text {b }}$, Shane O'Brien ${ }^{\text {c }}$, Mehmet Çopuroğlu ${ }^{\text {, }}$, Miao Cai a , \\ Richard Winfield ${ }^{\mathrm{c}}$, Alan Mathewson ${ }^{\mathrm{c}}$

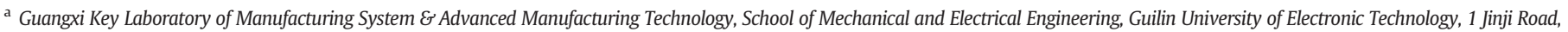 \\ Guilin 541004, Guangxi, China \\ ${ }^{\mathrm{b}}$ Department of Electrical and Electronic Engineering, University College Cork, Ireland \\ c Tyndall National Institute, University College Cork, Ireland \\ d Department of Chemistry, Bilkent University, 06800 Bilkent, Ankara, Turkey
}

\section{A R T I C L E I N F O}

Available online 7 January 2013

\section{Keywords:}

Loss tangent

PMNT

Thin films

Sol-gel

\begin{abstract}
A B S T R A C T
This work studies the impact of annealing temperatures on PMNT (lead-magnesium niobate-lead titanate, $\left.\mathrm{Pb}\left(\mathrm{Mg}_{0.33} \mathrm{Nb}_{0.67}\right)_{0.65} \mathrm{Ti}_{0.35} \mathrm{O}_{3}\right)$ thin films grown on a silicon substrate. The electrical properties of the thin films, such as dielectric constant and loss tangent, are shown to depend strongly on the annealing temperature, with the best electrical properties being achieved at the highest annealing temperature. It is seen that the perovskite phase is highest in the sample annealed at $750{ }^{\circ} \mathrm{C}$ indicating that a relatively high temperature is necessary for complete transition of PMNT to the perovskite phase. The sample annealed at $400{ }^{\circ} \mathrm{C}$ exhibits the lowest loss tangent of approximately 0.007 at a frequency of $1 \mathrm{MHz}$.
\end{abstract}

(c) 2013 Elsevier B.V. All rights reserved.

\section{Introduction}

PMNT (lead-magnesium niobate-lead titanate, $\mathrm{Pb}\left(\mathrm{Mg}_{0.33} \mathrm{Nb}_{0.67}\right)$ ${ }_{0.65} \mathrm{Ti}_{0.35} \mathrm{O}_{3}$ ) ferroelectric material has been shown to have promising characteristics for the formation of high-performance, low cost, thin films for integrated circuit (IC) applications. These thin films have high dielectric constants and low leakage currents and are therefore suitable for use as the insulator layers of high-density capacitors (with a high capacitance per unit area) in integrated circuits for small, low-power, portable, silicon electronic systems [1-3]. However, like any material system that is proposed for incorporation into an integrated circuit fabrication process, PMNT must be extensively characterised, and the trade-offs between processing conditions and the electrical performance understood, before the material can be considered for integration. This paper studies one of the important trade-offs, the annealing temperature, and outlines how the electrical properties of the PMNT thin films vary for a range of annealing temperatures from $400{ }^{\circ} \mathrm{C}$ to $750{ }^{\circ} \mathrm{C}$.

\section{Sample fabrication}

The PMNT thin films were grown on a $\mathrm{Pt}(111) / \mathrm{TiO}_{2} / \mathrm{SiO}_{2} / \mathrm{Si}$ substrate using a sol-gel technique [4-6]. All the chemicals employed were supplied by Sigma-Aldrich Co. $\mathrm{Mg}\left(\mathrm{C}_{2} \mathrm{H}_{5} \mathrm{O}\right)_{2}, \mathrm{Nb}\left(\mathrm{C}_{2} \mathrm{H}_{5} \mathrm{O}\right)_{5}, \mathrm{Ti}\left(\mathrm{n}-\mathrm{C}_{3} \mathrm{H}_{7} \mathrm{O}\right)_{4}$,

\footnotetext{
* Corresponding author. Tel.: + 8615907886352

E-mail address: cwb0201@163.com (W. Chen).
}

2-methoxyethanol (2ME), formamide and 1-hydroxy-cyclohexyl phenyl ketone (1HPK) were used as received. $\mathrm{Pb}\left(\mathrm{C}_{2} \mathrm{H}_{3} \mathrm{O}_{2}\right)_{2} \cdot 3 \mathrm{H}_{2} \mathrm{O}$ was dehydrated in a laboratory vacuum oven (Heraeus VT $5042 \mathrm{EK}$ ) at $70{ }^{\circ} \mathrm{C}$ for $16 \mathrm{~h}$ prior to use. A $0.5 \mathrm{M} \mathrm{Pb}\left(\mathrm{Mg}_{0.33} \mathrm{Nb}_{0.67}\right)_{0.6} 5 \mathrm{Ti}_{0.35} \mathrm{O}_{3}+15 \%$ $\mathrm{PbO}$ was synthesised by the sol-gel method, a flowchart of which is given in Fig. 1, resulting in a clear yellow/light brown sol. A stabiliser (formamide) amounting to $4 \%$ by volume was added. The precise concentration was adjusted by adding extra 2ME, where necessary. The sol-gel was spin-coated using a WS-400A-6NPP/LITE Spin-Coater (Laurell Technologies) at a spin rate of $3000 \mathrm{rpm}$ for $30 \mathrm{~s}$ at roomtemperature (RT). The coated wafers were then transferred onto a hot-plate, which had been set to $300{ }^{\circ} \mathrm{C}$ and kept at this temperature for approximately $1 \mathrm{~min}$. The wafers were then allowed to rest at RT for approximately $30 \mathrm{~s}$. The samples were then annealed using a Jipelec Jetfirst 150 rapid thermal processor at the desired annealing temperature in an $\mathrm{O}_{2}$ atmosphere [5]. The spin-coating and annealing cycles were repeated three times to obtain the desired film thicknesses. Samples were prepared with four annealing temperatures - these temperatures and the associated film thicknesses are as follows: $400{ }^{\circ} \mathrm{C}(128.2 \mathrm{~nm}), 450{ }^{\circ} \mathrm{C}(475 \mathrm{~nm}$, estimated $), 600{ }^{\circ} \mathrm{C}(147.6 \mathrm{~nm})$ and $750{ }^{\circ} \mathrm{C}(380 \mathrm{~nm})$.

Following growth and annealing of the PMNT layers, a composite top metal layer was deposited and patterned to form capacitor test structures which allow the dielectric properties of the PMNT to be measured. The composite top metal layer consists of $100 \mathrm{~nm}$ Pt and $200 \mathrm{~nm} \mathrm{Au}$. The Pt has good adhesion properties to the PMNT and the $\mathrm{Au}$ is used to reduce the overall resistance of the top metal layer and give good electrical contact to the probes used for measurement. 


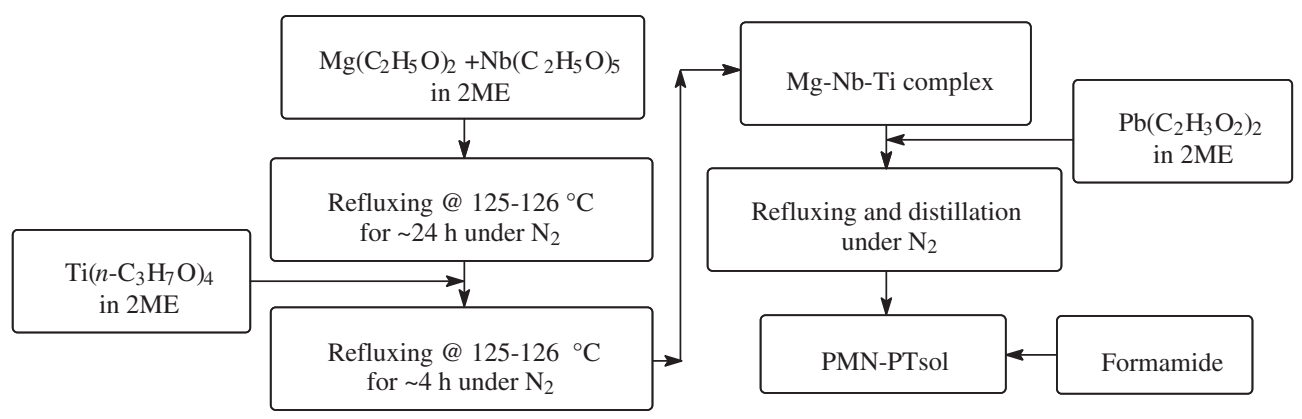

Fig. 1. Flowchart of the sol-gel synthesis process.

This top Pt/Au layer was patterned by photography and a lift-off process to create the final capacitor test structures. A cross-section and a top view of the test structures are shown in Fig. 2. Capacitors from the top metal layer to the underlying Pt layer are formed by simple square pad structures of dimensions $125 \mu \mathrm{m} \times 125 \mu \mathrm{m}$ as shown.

The crystal structure of the samples was determined by X-ray diffraction (XRD) using a PANalytical "X'Pert PRO XRD" system, using copper $K_{\alpha 1}$ radiation. XRD patterns were recorded in the normal $\Theta / 2 \Theta$ mode.

Scanning electron microscope (SEM) images were obtained using an FEI NovaNano 630, high-resolution, SEM instrument. The SEM accelerator voltage was adjusted to ensure good contrast, while mitigating the effects of charging, with a value of $20 \mathrm{kV}$ for the $400{ }^{\circ} \mathrm{C}$ and $600{ }^{\circ} \mathrm{C}$ samples and $6 \mathrm{kV}$ for the $750{ }^{\circ} \mathrm{C}$ sample.

The capacitance and loss tangent of the test capacitors were measured at zero-bias at frequencies up to $2 \mathrm{MHz}$ using an HP4284A precision LCR meter [3]. The capacitors were contacted by means of metal probes in an electrically and light-shielded probe station which were connected to the LCR meter by means of low-leakage, shielded cables. To zero any offsets in the system, the capacitance was first measured with the probes raised in the air above the samples and this offset was subtracted from the capacitance measured with the probes touching the samples. The dielectric constant was determined by rearrangement of the standard capacitance formula

$\mathrm{C}=\frac{\varepsilon_{\mathrm{O}} \varepsilon_{\mathrm{r}}}{\mathrm{t}_{\mathrm{D}}} \cdot \mathrm{A} \Rightarrow \varepsilon_{\mathrm{r}}=\frac{\mathrm{C}}{\mathrm{A}} \cdot \frac{\mathrm{t}_{\mathrm{D}}}{\varepsilon_{\mathrm{O}}}$
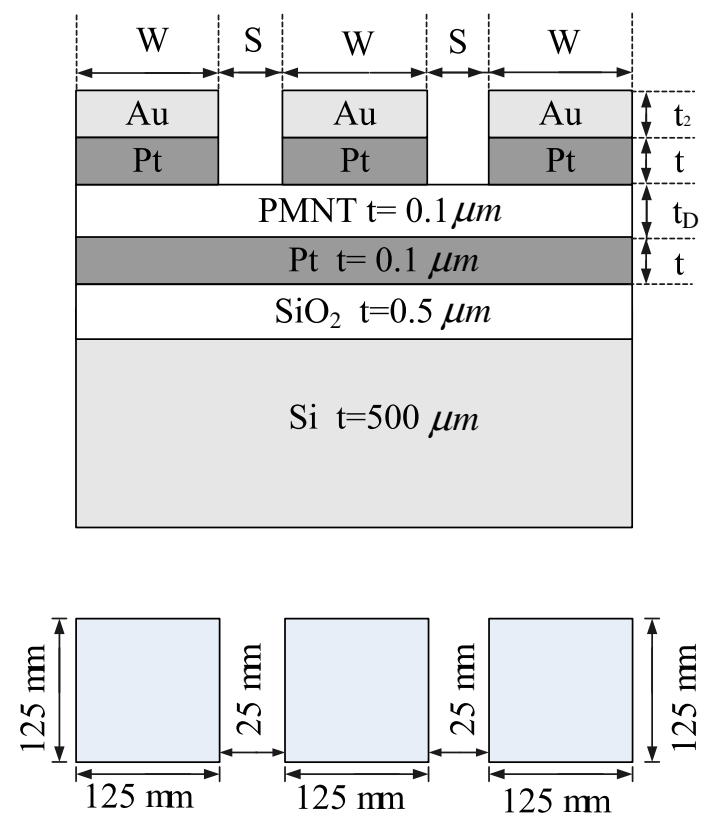

Fig. 2. Cross-section and top view of the fabricated capacitor test structures. where $\varepsilon_{\mathrm{o}}$ is the permittivity of free-space, $\varepsilon_{\mathrm{r}}$ is the relative permittivity (dielectric constant) of the dielectric thin film, $t_{D}$ is the thickness of the thin film and $\mathrm{A}$ is the area of the capacitor.

\section{Physical properties}

Fig. 3 shows the XRD data for PMNT samples annealed at $400{ }^{\circ} \mathrm{C}$, $600{ }^{\circ} \mathrm{C}$ and $750{ }^{\circ} \mathrm{C}$, respectively. The dominant peak in each of the plots corresponds to the perovskite phase of the material with the lower peaks corresponding to the pyrochlore phase and to the $\mathrm{Si}$ substrate. It is seen that the perovskite phase is highest in the sample annealed at $750{ }^{\circ} \mathrm{C}$ indicating that a relatively high temperature is necessary for complete transition of PMNT to the perovskite phase.

Fig. 4 shows the SEM images of the samples annealed at $400{ }^{\circ} \mathrm{C}$, $600{ }^{\circ} \mathrm{C}$ and $750{ }^{\circ} \mathrm{C}$, respectively. In these SEM images all the films appear dense and compact and there is no evidence of porosity (pinholes) in the films [6]. This is further evidenced by the very small leakage current in the films as indicated by the low loss tangents observed in the electrical measurements.

When the samples annealed at $400{ }^{\circ} \mathrm{C}$ and $600{ }^{\circ} \mathrm{C}$ were inspected in an optical microscope some areas of the samples displayed a green colour unlike the other samples. Such colour changes can indicate minor thickness inhomogeneity which can occur as part of the spinning process when excess liquid is pushed from the centre of the samples to the sides resulting in the films being thicker at the edges than in the centre. Electrical measurements were performed for both the normal and the coloured areas of these samples.

\section{Electrical properties}

Fig. 5 presents the electrical measurements for the samples annealed at different temperatures. In all cases, the thin films display a high dielectric constant accompanied by a low loss tangent. A general trend across all the samples is that the dielectric constant decreases with frequency across most of the frequency range and the loss tangent follows a similar trend. For calibration purposes, other test capacitors were fabricated with $\mathrm{SiO}_{2}$ as the dielectric layer and these samples displayed dielectric constant and loss tangent across the frequency range, indicating that the measurement setup was performing an accurate measurement over frequency and the behaviour indicated for the PMNT samples in Fig. 5 represents the intrinsic behaviour of the material and is not an artefact of the measurement setup.

Fig. 5 illustrates the strong relationship between the annealing temperature and the dielectric properties of the PMNT thin films. At a frequency of $1 \mathrm{MHz}$, the samples annealed at $400{ }^{\circ} \mathrm{C}$ have a dielectric constant of approximately 14 , those annealed at $450{ }^{\circ} \mathrm{C}$ have a dielectric constant of approximately 80 while the samples annealed at $750{ }^{\circ} \mathrm{C}$ achieve an exceptionally high dielectric constant of approximately 1115 . As indicated by the XRD data presented in Fig. 3, higher annealing temperatures favour the formation of the perovskite phase of the material compared to the pyrochlore phase 

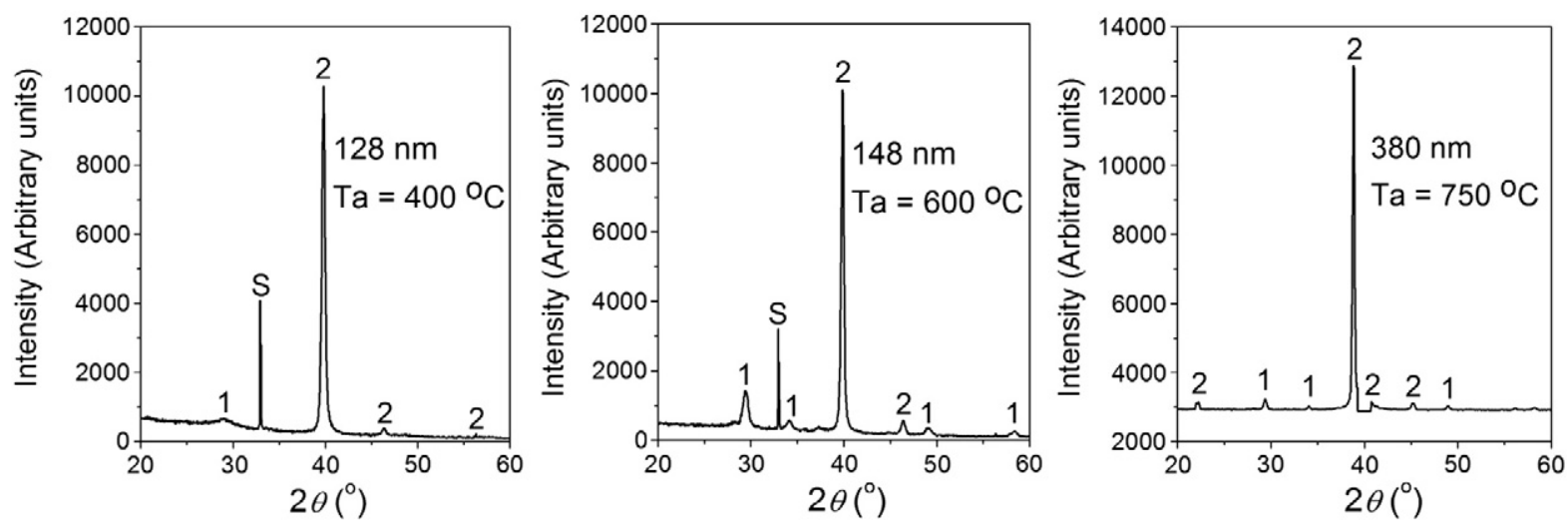

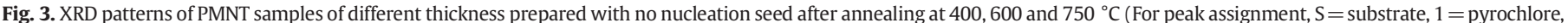
$2=$ perovskite)
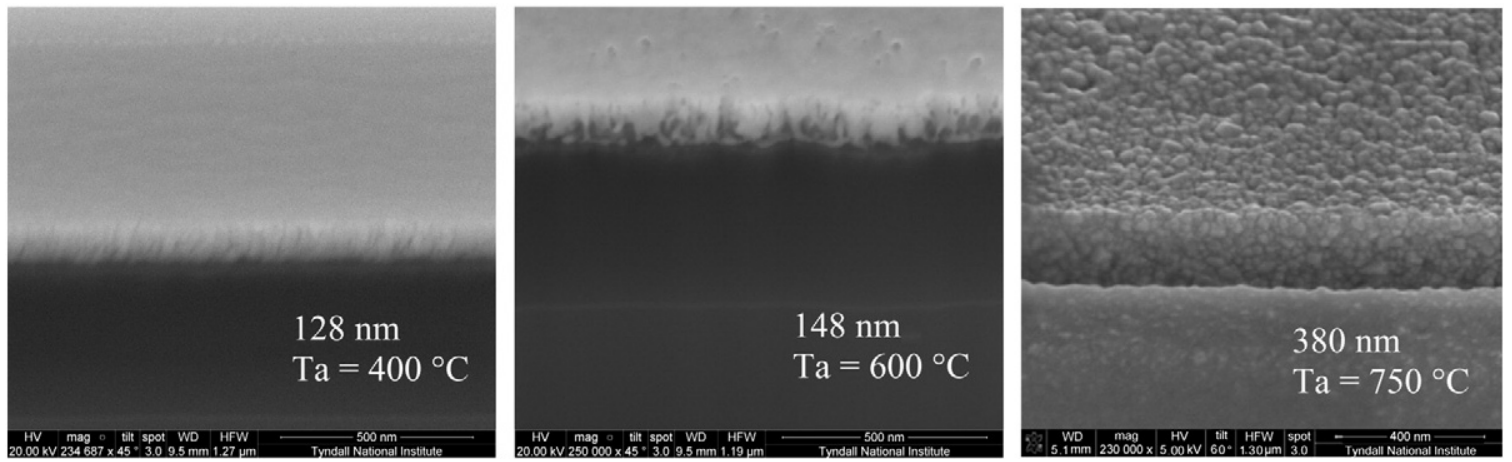

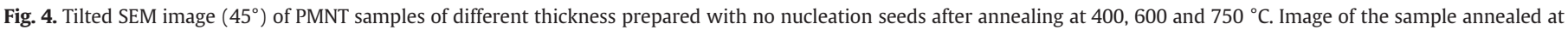
$750{ }^{\circ} \mathrm{C}$ is reproduced from [3].
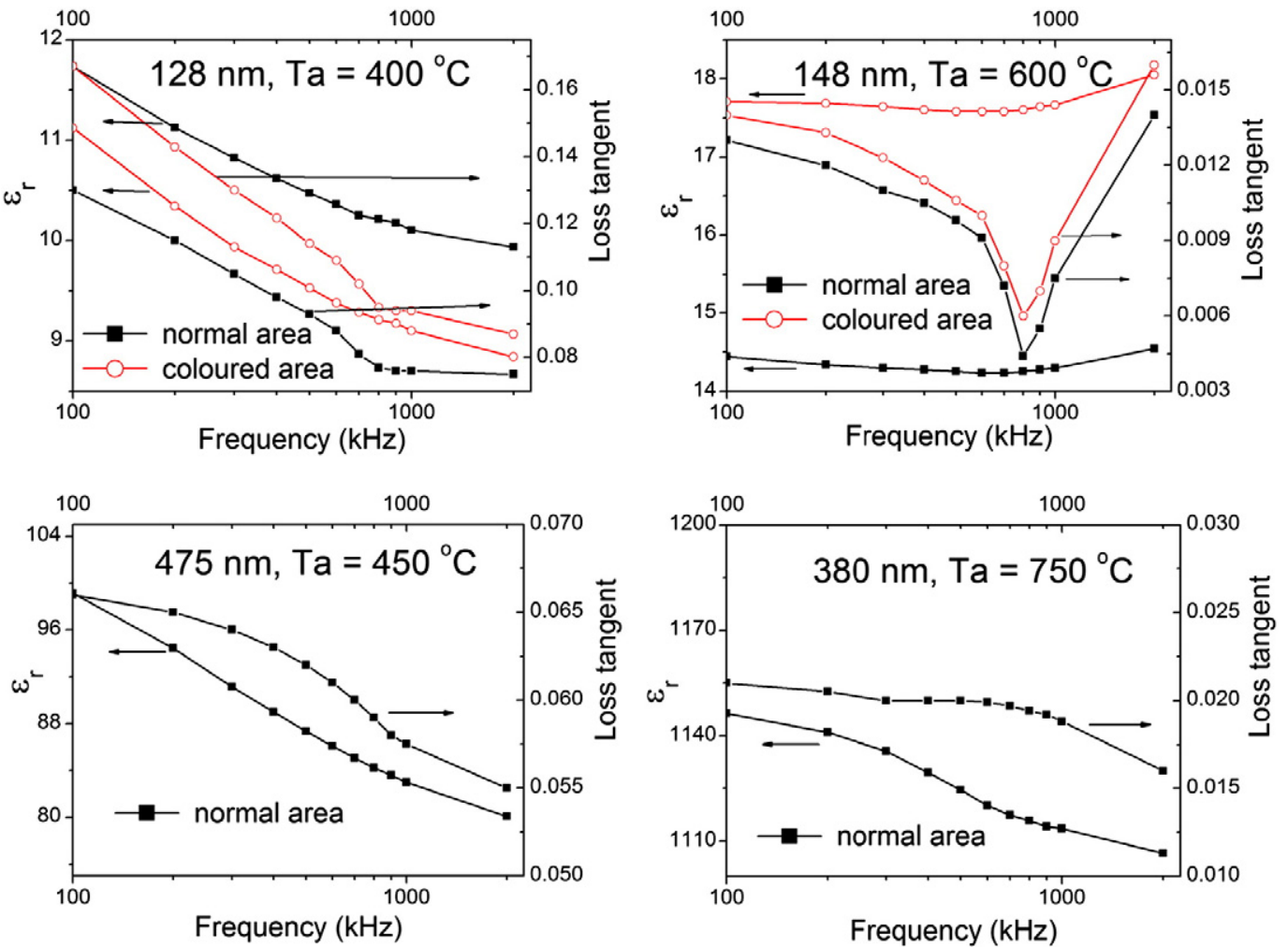

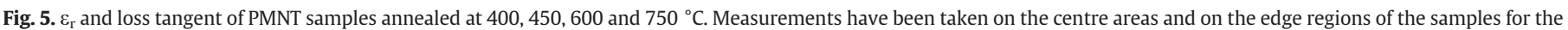
ones annealed at 400 and $600{ }^{\circ} \mathrm{C}$. 
at lower temperatures and the dielectric constant is thus seen to increase as the perovskite phase becomes dominant. The measurements shown in Fig. 5 indicate that the dielectric constant has improved by a factor of almost 100 when the annealing temperature changes from $400{ }^{\circ} \mathrm{C}$ to $750{ }^{\circ} \mathrm{C}$, indicating the dramatic difference between the pyrochlore and perovskite phases of the material. The loss tangent is low for all the samples shown. At a frequency of $1 \mathrm{MHz}$ it is lowest at approximately 0.007 for the sample annealed at $400{ }^{\circ} \mathrm{C}$ and rises to approximately 0.02 for the sample annealed at $750{ }^{\circ} \mathrm{C}$. While this indicates some degradation in the loss tangent for the sample annealed at $750{ }^{\circ} \mathrm{C}$, this would be an acceptable trade-off with the very high dielectric constant of approximately 1115 in many applications. The sample annealed at $600{ }^{\circ} \mathrm{C}$ follows the general trend in the loss tangent but deviates from the trend for the dielectric constant having the lowest dielectric constant of all the samples. For the samples with the colour variations, the measurements for the normal and coloured areas follow the same general trends with frequency but show slightly different values consistent with small variations in the thickness of the PMNT thin film layers.

\section{Conclusions}

The electrical characteristics of capacitor test structures based on the PMNT thin film layers have been presented. The electrical properties have been shown to be strongly influenced by the annealing temperature, with the dielectric constant changing by a factor of almost 100 as the annealing temperature is changed from $400{ }^{\circ} \mathrm{C}$ to $750{ }^{\circ} \mathrm{C}$, corresponding to the material changing from the pyrochlore phase to the perovskite phase. The results show that the perovskite phase is highest in the sample annealed at $750{ }^{\circ} \mathrm{C}$ indicating that a relatively high temperature is necessary for complete transition of PMNT to the perovskite phase. The sample annealed at $400{ }^{\circ} \mathrm{C}$ exhibits the lowest loss tangent of approximately 0.007 at a frequency of $1 \mathrm{MHz}$. PMNT is therefore a promising material for high density capacitor applications in future integrated circuit processes if the annealing temperature required to form the perovskite phase can be lowered.

\section{Acknowledgements}

This work was supported in part by the European Union Sixth Framework Programme through STREP project 033103 (CAMELIA). $W$. Chen also received support from PRTLI $4-$ NEMBES. Some of the measurements reported here were facilitated by Science Foundation Ireland National Access Programme, project NAP351. This research was also supported by Guangxi Key Laboratory of Manufacturing System \& Advanced Manufacturing Technology (Grant No. 11-031-12_001) and Guangxi Natural Science Foundation (2012GXNSFFA060010).

\section{References}

[1] E. Fribourg-Blanc, E. Cattan, D. Remiens, E. Defay, Solid State Electron. 47 (2003) 1631.

[2] X. Zhu, E. Defay, A. Suhm, E. Fribourg-blanc, M. Aid, Appl. Phys. Lett. 94 (12) (2009)

[3] W. Chen, K.G. McCarthy, A. Mathewson, M. Copuroglu, S. O'Brien, R. Winfield, IEEE Electron Device Lett. 3 (1/9) (2010) 996.

[4] D. Kuscer, J. Holc, M. Kosec, J. Am. Ceram. Soc. 90 (1) (2007) 29.

[5] W. Chen, K. McCarthy, M. Copuroglu, S. O'Brien, R. Winfield, A. Mathewson, Thin Solid Films 520 (2012) 4523.

[6] W. Chen, K. McCarthy, M. Copuroglu, H. Doyle, B. Malic, B. Kuznik, M. Kosec, S. O'Brien, R. Winfield, A. Mathewson, Thin Solid Films 519 (2011) 5800. 